\title{
Microstructural evolution of carbon fiber reinforced SiC-based matrix composites during laser ablation process
}

\author{
Xiaolin Dang ${ }^{\mathrm{a}}$, Xiaowei Yin ${ }^{\mathrm{a}, *}$, Xiaomeng Fan ${ }^{\mathrm{a}}$, Yuzhao Ma ${ }^{\mathrm{a}}$, Jiangtao Wang ${ }^{\mathrm{b}}$, Panfei Ju ${ }^{\mathrm{a}}$, \\ Hongwei Song ${ }^{\mathrm{b}}$ \\ a Science and Technology on Thermostructural Composite Materials Laboratory, Northwestern Polytechnical University, Xi'an 710072, China \\ ${ }^{\mathrm{b}}$ Key Laboratory for Mechanics in Fluid-Solid Coupling Systems, Institute of Mechanics, Chinese Academy of Sciences, Beijing 100190, China
}

\section{A R T I C L E I N F O}

\section{Article history:}

Received 30 August 2018

Received in revised form

30 November 2018

Accepted 14 April 2019

Available online 29 August 2019

\section{Keywords:}

Ablation performance

$\mathrm{C} / \mathrm{SiC}$ composite

Laser ablation

Mechanism

\begin{abstract}
A B S T R A C T
In this work, four different carbon fiber reinforced SiC-based matrix composites (C/SiC) were prepared, and microstructure evolution during laser ablation process was characterized. Laser irradiation provided a special high-temperature environment up to $3500^{\circ} \mathrm{C}$. For all four composites, different morphologies can be obtained in the transition region due to the oxidation of different matrices. While only needle-shaped carbon fiber and nanolayered carbon without any matrix remained in the central region, indicating that graphitization process occurred in the center, resulting from the high-temperature and low-oxygen environment in the laser process. Therefore, the laser ablation of $\mathrm{C} / \mathrm{SiC}$ composites is controlled by chemical and physical erosion, and mainly by the physical erosion in the center.
\end{abstract}

@ 2019 Published by Elsevier Ltd on behalf of The editorial office of Journal of Materials Science \& Technology.

\section{Introduction}

Carbon fiber reinforced $\mathrm{SiC}$ matrix composites $(\mathrm{C} / \mathrm{SiC})$ are typical ceramic matrix composites (CMCs), owning the low density, good thermal shock resistance, excellent oxidation resistance and outstanding mechanical strength at high temperatures [1-4]. They were widely used in aircraft engine, rocket nozzle and thermal protection system (TPS) of space vehicle as thermostructural materials $[5,6]$. Previous researches show that $\mathrm{C} / \mathrm{SiC}$ composites have good ablation performance in diverse ablations, such as oxyacetylene flame ablation, plasma wind tunnel ablation and arc-heated wind tunnel ablation [7-14]. Under these ablation conditions, ablation mechanism of $\mathrm{C} / \mathrm{SiC}$ composites have also been widely researched, indicating that the chemical erosion of oxidation reactions and the mechanical erosion of airflow dominated the ablation process $[7,9,15]$.

Recently, the rapid development of high-energy laser weapons presents new challenges for thermostructural materials [16-18]. Compared with ordinary ablation environments, the higher laser energy would be concentrated in smaller range because of the characteristics of laser irradiation. Thermostructural materials would be burned through the laser irradiation in a very short time, resulting

\footnotetext{
* Corresponding author.

E-mail address: yinxw@nwpu.edu.cn (X. Yin).
}

in destructive damage [19-22]. At present, some researches on laser ablation behaviors of thermostructural materials had been carried out, which were mainly focused on polymer matrix composites (PMCs), polymer and ultra-high temperature ceramic coatings [19,23-25]. However, the related studies on laser ablation performances of $\mathrm{C} / \mathrm{SiC}$ composites are hardly reported so far $[26,27]$. The laser ablation of PMCs is an irreversible one-time process which is accompanied by the conversion of materials. In contrast, the CMCs have a high melting point and the good thermal shock resistance, revealing great potential applied as laser ablation-resisted materials, which can be ablated repeatedly under laser irradiation. So, it is essential to study the laser ablation behavior of $\mathrm{C} / \mathrm{SiC}$ composites.

In this work, four $\mathrm{C} / \mathrm{SiC}$ composites with different matrices were prepared. The laser ablation behaviors of these composites were characterized, and the laser ablation mechanism was emphatically revealed.

\section{Experimental}

\subsection{Material preparation}

The carbon fiber preforms were prepared by three-dimensional needle (3DN) technology. The preparation is as follows: carbon fibers (PAN-based T300, Toray, Japan) were made into short-cut fiber webs and non-woven fiber cloths. And then, $0^{\circ}$ non-woven fiber cloth, short-cut fiber web, $90^{\circ}$ non-woven fiber cloth and 
Table 1

Basic parameters of YLS-2000 IPG fiber laser.

\begin{tabular}{ll}
\hline Parameters & Value \\
\hline Laser power $(\mathrm{W})$ & 2000 \\
Laser beam radius $(\mathrm{mm})$ & 5 \\
Laser radiation time $(\mathrm{s})$ & 10 \\
Laser wavelength $(\mathrm{nm})$ & 1070 \\
Ambient temperature $\left({ }^{\circ} \mathrm{C}\right)$ & 20 \\
\hline
\end{tabular}

another short-cut fiber web were stacked in sequence and connected by needling carbon fibers using the needle-punching technique [28].

Porous $\mathrm{C} / \mathrm{SiC}$ preforms were fabricated by the similar process to our previous studies $[7,28]$. Pyrocarbon $(\mathrm{PyC})$ interphase with a thickness of $200 \mathrm{~nm}$ was deposited on carbon fiber preforms by chemical vapor infiltration (CVI). The preforms were heat-treated at $1800^{\circ} \mathrm{C}$ for $2 \mathrm{~h}$ under vacuum. Sequentially, the $\mathrm{SiC}$ matrix was infiltrated by the CVI process to fabricate porous $\mathrm{C} / \mathrm{SiC}$ preforms.

The $\mathrm{SiC}$ matrix was introduced into porous $\mathrm{C} / \mathrm{SiC}$ preforms by the CVI for $240 \mathrm{~h}$, which were named as $\mathrm{C} / \mathrm{SiC}$. The porous $\mathrm{C} / \mathrm{SiC}$ preforms were placed in a vacuum furnace, and liquid silicon was infused at $1500^{\circ} \mathrm{C}$ for $30 \mathrm{~min}$, which were named as $\mathrm{C} / \mathrm{SiC}$ $\mathrm{Si}$. The porous $\mathrm{C} / \mathrm{SiC}$ preforms were infiltrated with TiC slurry to obtain $\mathrm{C} / \mathrm{SiC}-\mathrm{TiC}$. The slurry was prepared by dispersing $\mathrm{TiC}$ powder (1-2 $\mu \mathrm{m}, 60 \mathrm{wt} . \%)$ in deionized water and then ball milled for $24 \mathrm{~h}$.

After slurry infiltration of TiC slurry, the C/SiC-TiC was infiltrated with liquid silicon by liquid silicon infiltration (LSI) method at $1500^{\circ} \mathrm{C}$ under vacuum for $30 \mathrm{~min}[7,29]$. The as-received samples were named as $\mathrm{C} / \mathrm{SiC}-\mathrm{TiSi}_{2}$. Also after the slurry infiltration, the $\mathrm{C} / \mathrm{SiC}-\mathrm{TiC}$ was placed in a vacuum furnace, with Al-Si alloy (40 wt.\% Al, 60 wt.\% Si, HuaweiRuike Co. Ltd., Beijing, China) placed on the surfaces. The Al-Si alloy was infiltrated by reactive melt infiltration (RMI) for $2 \mathrm{~h}$ at $1300^{\circ} \mathrm{C}$ to obtain the composites called $\mathrm{C} / \mathrm{SiC}-\mathrm{Ti}_{3} \mathrm{Si}(\mathrm{Al}) \mathrm{C}_{2}$.

\subsection{Laser ablation test}

The laser ablation setup in this work is YLS-2000 IPG fiber laser (Key Laboratory for Mechanics in Fluid-Solid Coupling Systems, Institute of Mechanics, Chinese Academy of Sciences, Beijing China). The main performance parameters of this device are listed in Table 1. During ablation tests, the sample was placed on top of the fixture and laser was ablated vertically at an angle of $90^{\circ}$. The size of samples for ablation tests is $\Phi 30 \mathrm{~mm} \times 5 \mathrm{~mm}$. The whole experiments were carried out in air.

The thickness and mass of samples were measured before and after laser ablation experiment. The line ablation rate (LAR) $R \mathrm{l}$ $(\mathrm{mm} / \mathrm{s})$ and the mass ablation rate (MAR) $R \mathrm{~m}(\mathrm{~g} / \mathrm{s})$ of the sample were calculated according to the following formulas:

$R_{\mathrm{l}}=\frac{l_{0}-l_{\mathrm{t}}}{t}$

$R_{\mathrm{m}}=\frac{m_{0}-m_{\mathrm{t}}}{t}$

where, $l_{0}$ and $l_{\mathrm{t}}$ are the ablation center thickness $(\mathrm{mm})$ before and after ablation, $m_{0}$ and $m_{\mathrm{t}}$ are the sample weight before and after ablation $(\mathrm{g}), t$ is the ablation time (s).

\subsection{Characterization}

The morphologies of samples were observed by scanning electron microscope (SEM, Hitachi-S4700, Japan) and back-scattered electron image (BSE). The chemical composition was examined by energy dispersive spectroscopy (EDS). The phases were identified by X-ray diffraction (XRD, RIGAKU D/Max-2400, Tokyo, Japan)

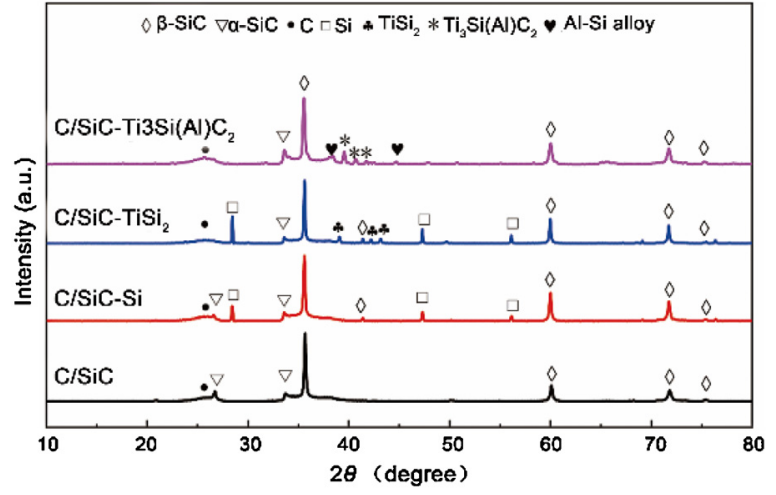

Fig. 1. XRD patterns of four different composites powder.

using a Ni-filtered $\mathrm{Cu} \mathrm{K} \alpha$ radiation at a scanning rate of $5^{\circ} / \mathrm{min}$ and scanning from $10^{\circ}$ to $80^{\circ}$ of $2 \theta$. The ablated surface of samples was observed by continuous variable stereomicroscope (XTL-25, Shanghai, China). The bulk density and open porosity of materials were measured using the Archimedes drainage method according to ASTM C-20 standard.

\subsection{Numerical simulation}

Through numerical simulation, a $1 / 4$ ablation model $(17.5 \mathrm{~mm} \times 17.5 \mathrm{~mm} \times 3.5 \mathrm{~mm})$ was established by commercial software ANSYS. Finite element method (FEM) was used to study the laser ablation process which is mainly expressed in terms of the enthalpy of each phase. During the simulation progress, main physicochemical processes of laser ablation were considered, such as thermal conduction, heat radiation, oxidation and sublimation. The Stefan-Boltzmann constant is $5.67 \times 10^{-8}$ $\mathrm{W} \cdot \mathrm{m}^{-2} \mathrm{~K}^{-4}$ and surface emissivity is 0.8 . The basic thermophysical properties of materials are from previous studies [30].For example, the specific heat of $\mathrm{C} / \mathrm{SiC}$ composites is $1656 \mathrm{~J} \cdot \mathrm{kg}^{-1} \mathrm{~K}^{-1}$, the latent heat of $\mathrm{SiC}$ and $\mathrm{C}$ are $19.83 \mathrm{MJ} / \mathrm{kg}$ and $59.45 \mathrm{MJ} / \mathrm{kg}$ respectively.

\section{Results and discussion}

\subsection{Microstructure and phase composition}

These four composites were crushed into powder and then the phase composition was detected. The XRD patterns of these four composites are shown in Fig. 1. It can be seen that $\mathrm{C} / \mathrm{SiC}$ is composed of carbon, $\alpha$-SiC and $\beta$-SiC. C/SiC-Si is composed of carbon, $\alpha-S i C$, $\beta$-SiC and silicon. As a contrast, $\mathrm{C} / \mathrm{SiC}-\mathrm{TiSi}_{2}$ is composed of carbon, $\alpha-\mathrm{SiC}, \beta-\mathrm{SiC}, \mathrm{TiSi}_{2}$ and residual silicon. $\mathrm{C} / \mathrm{SiC}-\mathrm{Ti}_{3} \mathrm{Si}(\mathrm{Al}) \mathrm{C}_{2}$ is composed of carbon, $\alpha-\mathrm{SiC}, \beta-\mathrm{SiC}, \mathrm{Ti}_{3} \mathrm{Si}(\mathrm{Al}) \mathrm{C}_{2}$ and residual Al-Si alloy. In addition, the bulk density and open porosity of these samples were measured, i.e. $2.10 \mathrm{~g} / \mathrm{cm}^{3}$ and 18.0 vol.\% for $\mathrm{C} / \mathrm{SiC}, 2.14 \mathrm{~g} / \mathrm{cm}^{3}$ and 16.2 vol.\% for C/SiC-Si, $2.18 \mathrm{~g} / \mathrm{cm}^{3}$ and 16.1 vol.\% for C/SiC-TiSi 2 , $2.25 \mathrm{~g} / \mathrm{cm}^{3}$ and 15.8 vol.\% for $\mathrm{C} / \mathrm{SiC}-\mathrm{Ti}_{3} \mathrm{Si}(\mathrm{Al}) \mathrm{C}_{2}$.

Fig. 2 presents the BSE images of polished cross-section of all four samples. As shown in Fig. 2(a), there were large pores locating in $\mathrm{C} / \mathrm{SiC}$. After the densification of composites, as can be seen from Fig. 2(b), (c) and (d), large pores were filled. Combined with XRD results, for $\mathrm{C} / \mathrm{SiC}-\mathrm{Si}$, the matrices were composed of $\mathrm{Si}$ (the brightest phase) and $\mathrm{SiC}$. For $\mathrm{C} / \mathrm{SiC}-\mathrm{TiSi}_{2}$, the introduced matrices were composed of $\mathrm{TiSi}_{2}$ (the brightest phase), $\mathrm{Si}$ (the next brightest phase that wrapped $\mathrm{TiSi}_{2}$ around), and newly generated $\mathrm{SiC}$ (the dark grey particles). For $\mathrm{C} / \mathrm{SiC}-\mathrm{Ti}_{3} \mathrm{Si}(\mathrm{Al}) \mathrm{C}_{2}$, introduced matrices were composed of $\mathrm{Ti}_{3} \mathrm{Si}(\mathrm{Al}) \mathrm{C}_{2}$ and residual Al-Si alloy.

As a result, the $\mathrm{SiC}$-based matrices are dissimilar owing to different preparation processes, with porous $\mathrm{SiC}$ for $\mathrm{C} / \mathrm{SiC}$, silicon phase 


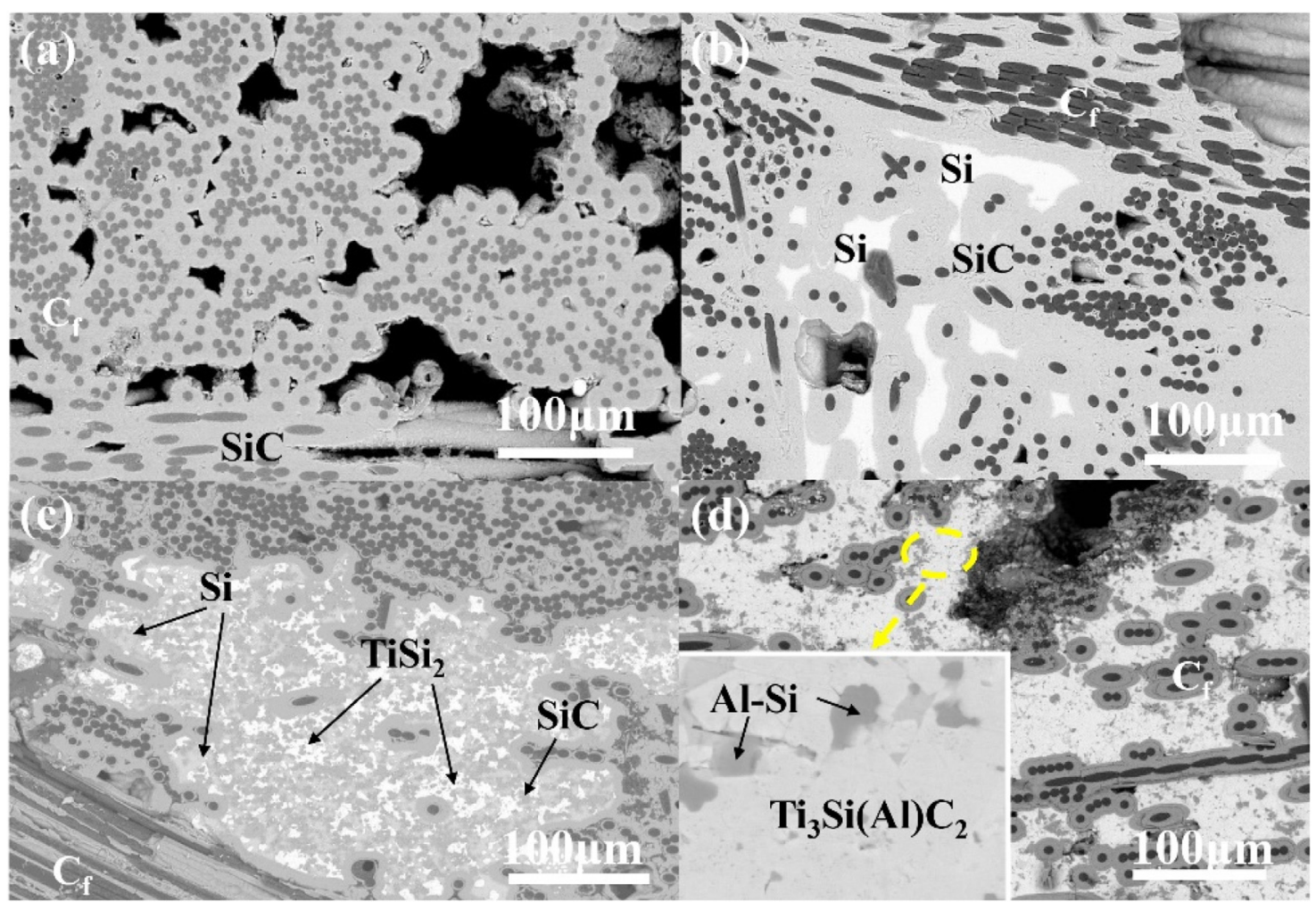

Fig. 2. BSE images of polished surface: (a) C/SiC, (b)C/SiC-Si, (c)C/SiC-TiSi, (d) C/SiC-Ti $3 \mathrm{Si}_{2}(\mathrm{Al}) \mathrm{C}_{2}$.

Table 2

Mass and linear ablation rate of four different $\mathrm{C} / \mathrm{SiC}$ composites.

\begin{tabular}{lll}
\hline Samples & $\begin{array}{l}\text { Mass ablation rate } \\
(\mathrm{mg} / \mathrm{s})\end{array}$ & $\begin{array}{l}\text { Linear ablation rate } \\
(\mathrm{mm} / \mathrm{s})\end{array}$ \\
\hline $\mathrm{C} / \mathrm{SiC}$ & 8.3 & 0.087 \\
$\mathrm{C} / \mathrm{SiC}-\mathrm{Si}$ & 4.9 & 0.067 \\
$\mathrm{C} / \mathrm{SiC}-\mathrm{TiSi}_{2}$ & 4.5 & 0.077 \\
$\mathrm{C} / \mathrm{SiC}-\mathrm{Ti}_{3} \mathrm{Si}(\mathrm{Al}) \mathrm{C}_{2}$ & 3.8 & 0.079 \\
\hline
\end{tabular}

Table 3

Graphitization degree of four composites after laser ablation (according to (002) characteristic peak).

\begin{tabular}{lllll}
\hline Composites & $2 \theta\left(^{\circ}\right)$ & FWHM $\left({ }^{\circ}\right)$ & $\mathrm{d}_{002}(\mathrm{~nm})$ & $\mathrm{G}(\%)$ \\
\hline $\mathrm{C} / \mathrm{SiC}$ & 26.0377 & 0.7872 & 0.3422 & 20.93 \\
$\mathrm{C} / \mathrm{SiC}-\mathrm{Si}$ & 26.2339 & 0.1056 & 0.3394 & 53.49 \\
$\mathrm{C} / \mathrm{SiC}-\mathrm{TiSi}_{2}$ & 26.5111 & 0.1584 & 0.3359 & 94.19 \\
$\mathrm{C} / \mathrm{SiC}-\mathrm{Ti}_{3} \mathrm{Si}(\mathrm{Al}) \mathrm{C}_{2}$ & 26.4785 & 0.2880 & 0.3363 & 89.53 \\
\hline
\end{tabular}

for $\mathrm{C} / \mathrm{SiC}-\mathrm{Si}$, Ti-Si-C phase for $\mathrm{C} / \mathrm{SiC}-\mathrm{TiSi}_{2}$ and $\mathrm{Ti}-\mathrm{Si}-\mathrm{Al}-\mathrm{C}$ phase for $\mathrm{C} / \mathrm{SiC}-\mathrm{Ti}_{3} \mathrm{Si}(\mathrm{Al}) \mathrm{C}_{2}$.

\subsection{Laser ablation behavior}

The laser ablation properties of these four composites are shown in Table 2. In general, the MAR represents the mass change rate of the whole materials, while the LAR represents the depth change rate of the worst ablation area. Therefore, the higher MAR and LAR means more rapid loss of the mass and more serious erosion in the center. As listed in Table 2, the LAR of these four composites did not appear to be much different. Meanwhile, the MAR results indicated that the introduced matrices, such as $\mathrm{Ti}_{3} \mathrm{Si}(\mathrm{Al}) \mathrm{C}_{2}$ phase, were helpful to reduce the mass loss of $\mathrm{C} / \mathrm{SiC}$ composites.

Fig. 3 shows the XRD patterns on the surface of samples after laser ablation process. The major surface composition of $\mathrm{C} / \mathrm{SiC}$ and $\mathrm{C} / \mathrm{SiC}-\mathrm{Si}$ are $\mathrm{SiC}$ and carbon. Oxides also existed on the surface of

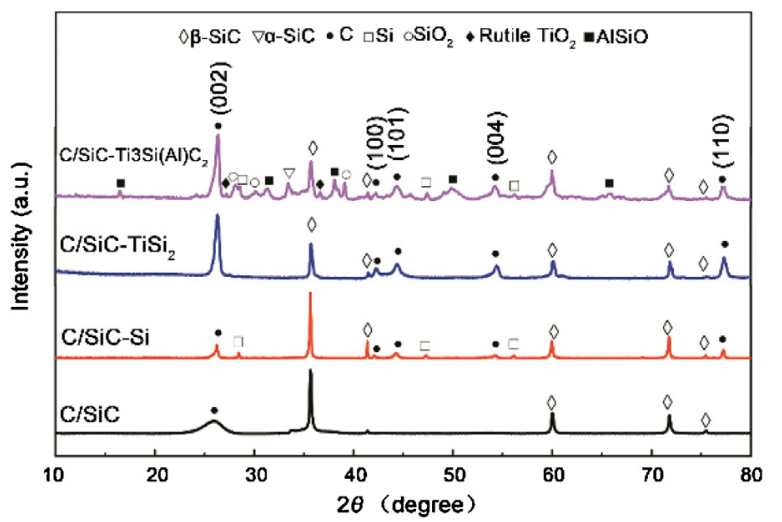

Fig. 3. XRD patterns on laser ablation surface of four different $\mathrm{C} / \mathrm{SiC}$ composites.

$\mathrm{C} / \mathrm{SiC}-\mathrm{TiSi}_{2}$ and $\mathrm{C} / \mathrm{SiC}-\mathrm{Ti}_{3} \mathrm{Si}(\mathrm{Al}) \mathrm{C}_{2}$. For $\mathrm{C} / \mathrm{SiC}-\mathrm{TiSi}_{2}$, oxidation products were mainly composed of $\mathrm{SiO}_{2}$ and $\mathrm{TiO}_{2}$. For $\mathrm{C} / \mathrm{SiC}-\mathrm{Ti}_{3} \mathrm{Si}(\mathrm{Al}) \mathrm{C}_{2}$, a large amount of oxides such as $\mathrm{SiO}_{2}, \mathrm{TiO}_{2}$ and $\mathrm{AlSiO}$ could be observed. It is noted that high carbon peaks could be observed from $\mathrm{XRD}$ results of all these four composites.

According to the result of high carbon peaks, it can be considered that high-temperature graphitization process occurred during laser ablation. Graphitization degree, which can be calculated from the XRD results, refers to the degree of similarity between the arrangement of carbon atom of samples and the crystal structure of graphite. According to previous researches, interlayer spacing of the (002) planes was measured and substituted into MeringMaire formula (also known as Franklin formula) to calculate the graphitization degree [31]:

$G=\frac{0.3440-d_{002}}{0.3440-0.3354} \times 100 \%$ 

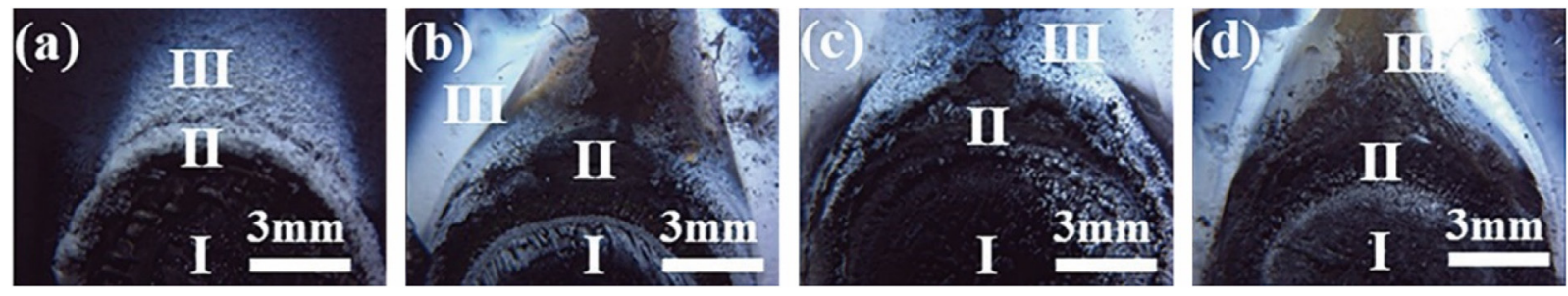

Fig. 4. Macroscopic images of laser ablation surface: (a) 3DN C/SiC, (b) $3 \mathrm{DN} \mathrm{C} / \mathrm{SiC}-\mathrm{Si}$, (c) $3 \mathrm{DN} \mathrm{C} / \mathrm{SiC}^{-\mathrm{TiSi}} \mathrm{i}_{2},(\mathrm{~d}) 3 \mathrm{DN} \mathrm{C} / \mathrm{SiC}-\mathrm{Ti}_{3} \mathrm{Si}(\mathrm{Al}) \mathrm{C}_{2}$.

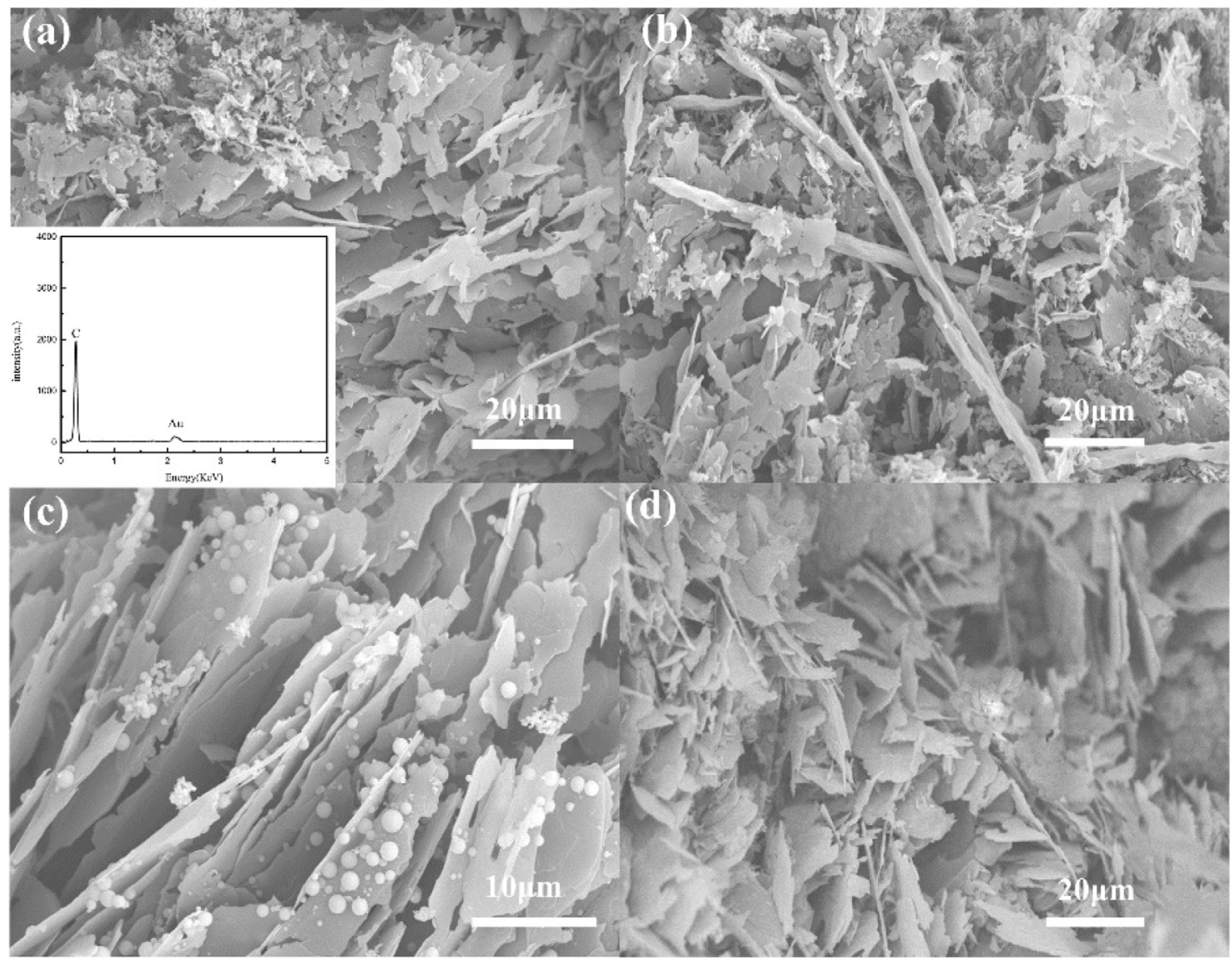

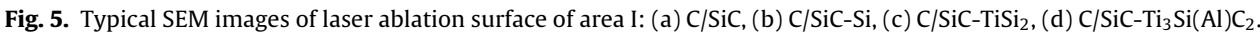

where $G$ is graphitization degree (\%). 0.3440 is the interlayer spacing of completely non-graphitized carbon (nm). 0.3354 is the interlayer spacing of ideal graphite crystals, which is also a half of the $c$-axis lattice constant of hexagonal graphite $(\mathrm{nm}) . d_{002}$ is the interlayer spacing of (002) planes of samples ( $\mathrm{nm}$ ).

After the laser ablation process, the graphitization degree of these four composites were listed in Table 3. According to the calculation results, it can be seen that $\mathrm{C} / \mathrm{SiC}-\mathrm{TiSi}_{2}$ and $\mathrm{C} / \mathrm{SiC}-\mathrm{Ti}_{3} \mathrm{Si}(\mathrm{Al}) \mathrm{C}_{2}$ exhibit higher levels of graphitization degree. These four composites were composed of same preform and different SiC-based matrices, but the graphitization degree was different. This difference was caused by the different SiC-based matrices which have different abilities to the consumption of oxygen. So, it can be inferred that the oxygen consumption may influence the degree of graphitization. The introduction of Ti-Si-C and Ti-Si-Al-C matrices could accelerate the consumption of oxygen. The special lowoxygen environment would be formed more quickly, promoting the process of high-temperature graphitization.

The macroscopic images of laser ablation surface are shown in Fig. 4. Depending on the appearance of ablation surface and the dis- tinct temperature gradient during ablation process, ablated area can be divided into three regions: the center region (area I), the transition region (area II) and the edge region (area III). In the laser ablation experiment of this work, the spot diameter of laser beam is $10 \mathrm{~mm}$. Due to the good directivity and small divergence of laser beam, it has formed inverted conical ablation pit on samples which has a diameter of around $10 \mathrm{~mm}$. This area is the worst-damaged part, which was called as the center region. Radially outwardly, a narrower circle of massive particulates can be observed around the ablation pit, and this region is the transition region. Surrounded by this region, continuous white oxide layer covers on the surface. It could be observed that the coverage area is also the area where had been ablated by flame. This area is the edge region. Out of these three regions, there was hardly any damage or crack on the surface, which is benefited from good thermal shock resistance of $\mathrm{C} / \mathrm{SiC}$ composites.

After laser ablation, the residue found in the central part of area I mainly were black particles. Besides that, there were lots of needleshaped carbon fibers in the edge part of area I. Since the whole experiments were carried out in air, the atmosphere is composed 


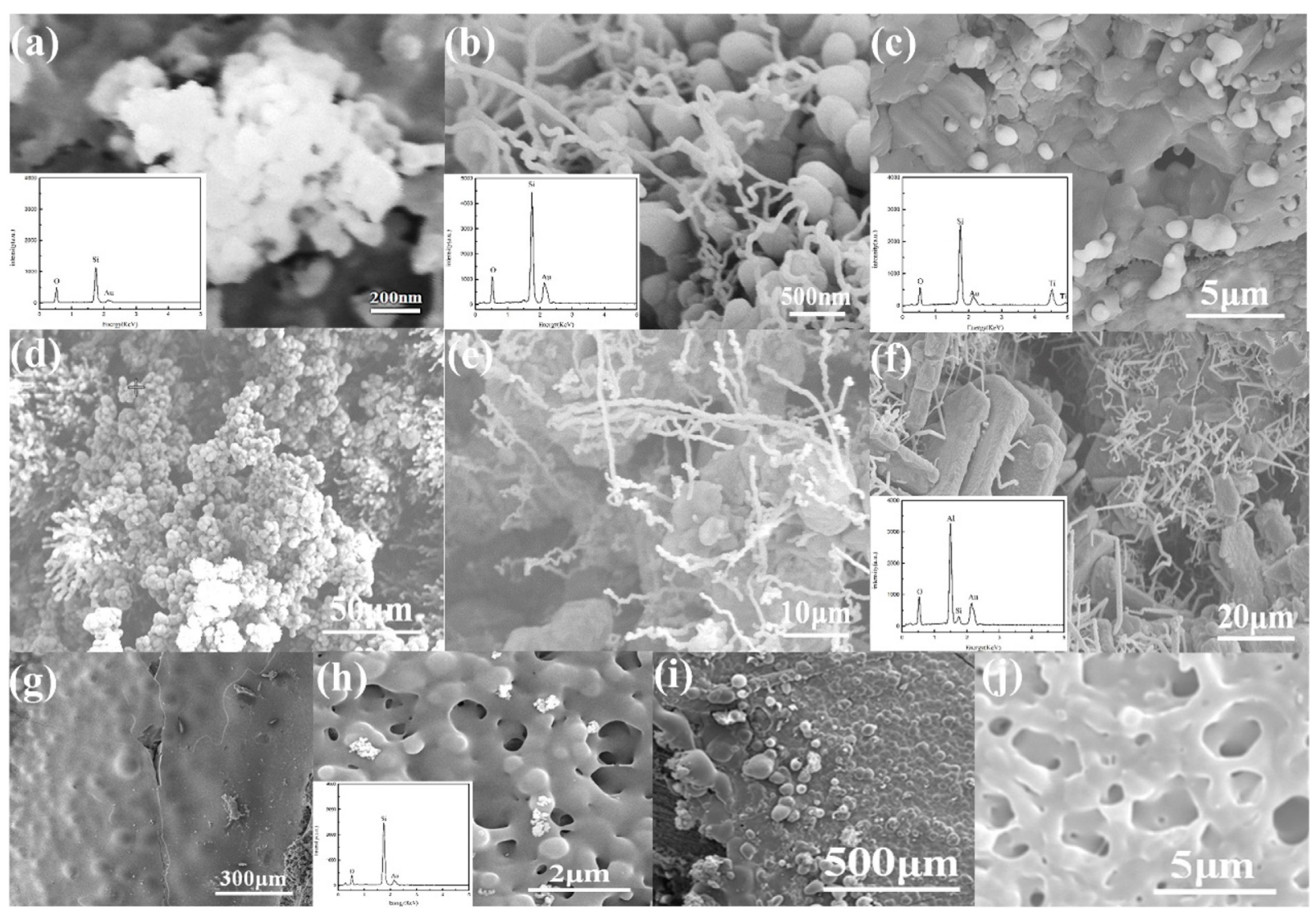

Fig. 6. SEM images of laser ablation surface of the transition region: (a) C/SiC, (b) C/SiC-Si, (c)(d)(e) C/SiC-TiSi, , (f) C/SiC-Tii $3 \mathrm{Si}(\mathrm{Al}) \mathrm{C}_{2}$ and the edge region: (g) C/SiC, (h) C/SiC-Si, (i) $\mathrm{C} / \mathrm{SiC}-\mathrm{TiSi}_{2}$, (j) $\mathrm{C} / \mathrm{SiC}-\mathrm{Ti}_{3} \mathrm{Si}(\mathrm{Al}) \mathrm{C}_{2}$.
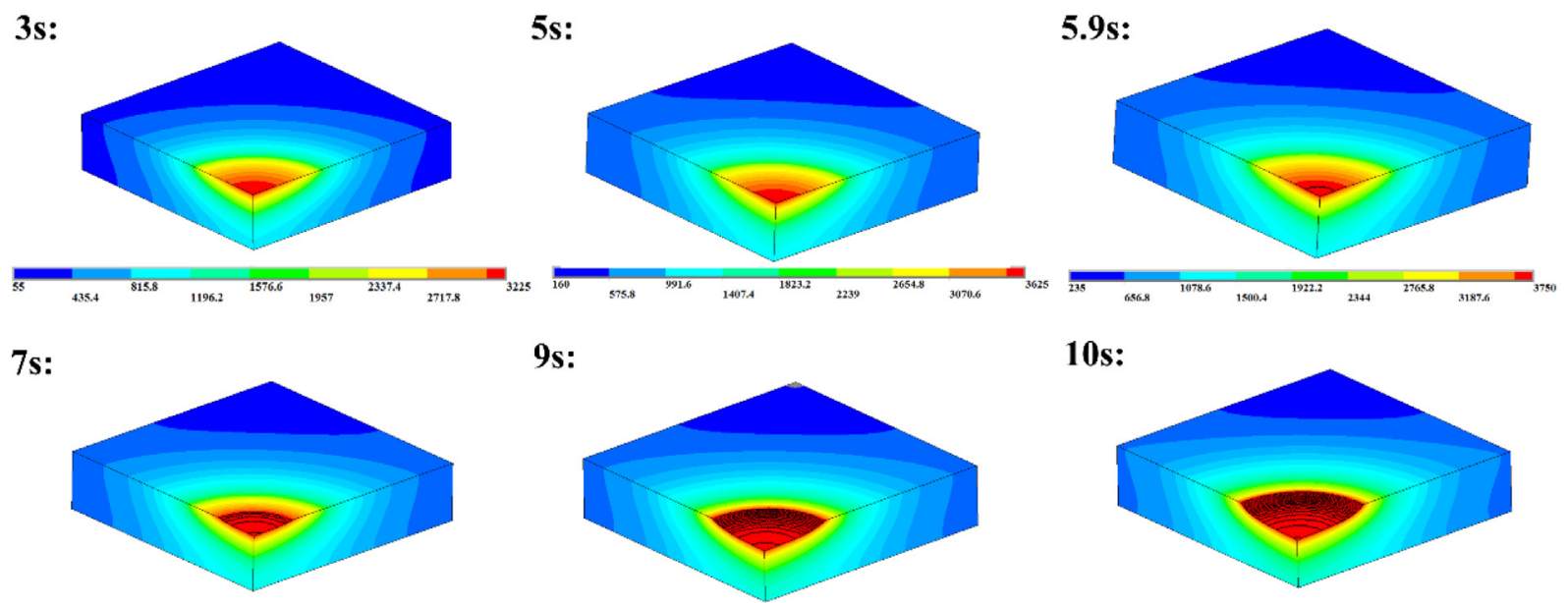

9s:
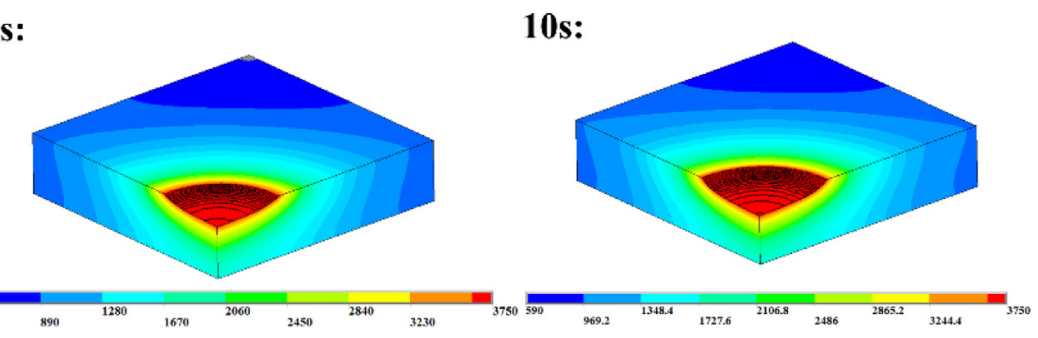

Fig. 7. Simulated temperature field nephogram during the laser ablation process $(\mathrm{C} / \mathrm{SiC})$.

of oxidizing species, which would take part in combustion reaction. Thus, oxidation reactions also occurred during the laser ablation. With the introduction of low melting point phases, the generated oxides covered on surface increased. The presence of oxides has good consistency with the results of MAR.

The typical microphotograph of laser ablation surface of area I are shown in Fig. 5. There were lots of nanolayered carbon in the central part of area I. As mentioned above, these carbon phases were mainly generated by high-temperature graphitization process during laser ablation process. The carbon atoms may come from the decomposition of SiC-based matrices and the sublimation of part of carbon fibers at ultra-high temperature. This process is regarded to be similar with the formation of singlewall carbon nanotube by laser ablation [32]. It indicated that the $\mathrm{C} / \mathrm{SiC}$ composites with different matrices have the same ablated morphology in the center region, only the nanolayered carbon remains. This result is consistent with the similar LAR results of these four samples in the experiment. And the large amount of residue of carbon phases had been proved by the XRD results in Fig. 3. 


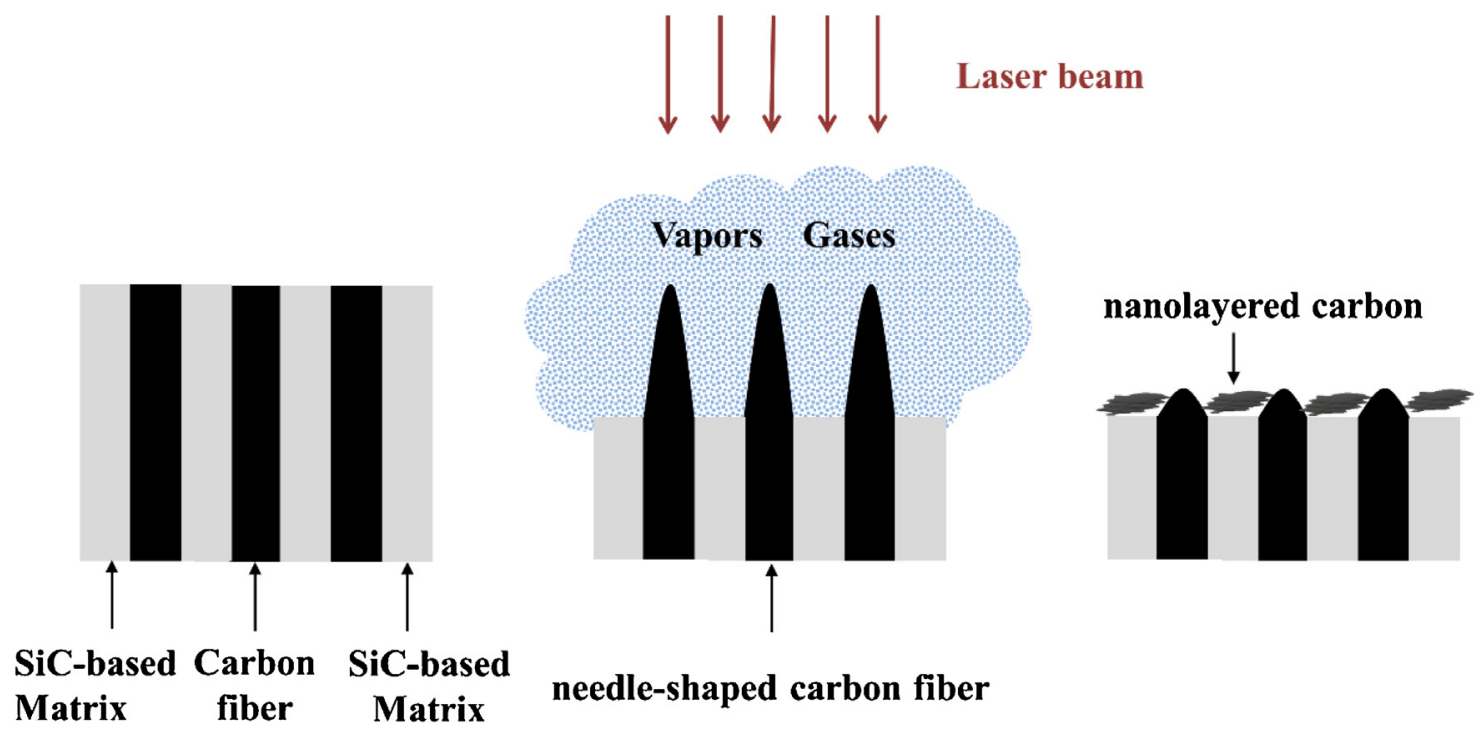

Fig. 8. Schematic diagram of laser ablation mechanism in the center of $\mathrm{C} / \mathrm{SiC}$ composites.

In the transition region, surface temperature is lower than that in area I and higher than area III. As shown in Fig. 6, in this region, the laser ablation is dominated by the oxidation processes, so many oxides with a diversity of morphologies were formed in area II. For C/SiC, EDS result shows that the granular substance is mainly composed of $\mathrm{SiO}_{2}$, as shown in Fig. 6(a). For C/SiC-Si, what the most remarkable is the formation of silicon oxide nanowires during the laser ablation (Fig. 6(b)). Previous researches revealed that the growth mechanism of oxide nanowires is mainly controlled by gas-liquid-solid (VLS) growth mechanism driven by temperature gradient $[33,34]$. For $\mathrm{C} / \mathrm{SiC}-\mathrm{TiSi}_{2}, \mathrm{TiO}_{2}$ and $\mathrm{SiO}_{2}$ would be formed by oxidation reaction. The massive phase and the spherical phase are $\mathrm{TiO}_{2}$ and $\mathrm{SiO}_{2}$, respectively (Fig. 6(c)). At the same time, it is possible to find the granular silicon oxides (Fig. 6(d)) and silicon oxide nanowires (Fig. 6(e)) in the transition region. For $\mathrm{C} / \mathrm{SiC}-\mathrm{Ti}_{3} \mathrm{Si}(\mathrm{Al}) \mathrm{C}_{2}$, combined with the results of EDS and XRD, the main component of formed oxide is AlSiO phase (Fig. 6(f)).

The temperature on the surface in the edge region is lowest, and heat is only derived from heat conduction without the direct irradiation of laser beam. In the edge region, there were large amorphous oxide phases. In this region, continuous oxide film can be observed on the ablated surface (Figs. 6(g)-(j)). During the laser ablation process, the amorphous oxide melt, such as $\mathrm{SiO}_{2}, \mathrm{TiO}_{2}$ and $\mathrm{AlSiO}$, are mixed into a homogenous melt to cover the ablated surface and form the continuous oxide film in the edge region.

The presence of oxides film improves the laser ablation performance of composites because it can effectively protect the matrices and fibers from further damage and prevent the inward diffusion of oxygen [7].

\subsection{Laser ablation mechanism}

As analysis above, the condition of laser ablation behavior is different from other ablation environments. Thus, the laser ablation mechanism of $\mathrm{C} / \mathrm{SiC}$ composites should be analyzed in detail.

The distribution of temperature field was calculated by numerical simulation using FEM. In order to reduce the influencing factors and research essential laser ablation mechanism, only $\mathrm{C} / \mathrm{SiC}$ was studied by numerical simulation method (Fig. 7). According to the simulation results, the surface temperature in the center region reached more than $3500^{\circ} \mathrm{C}$, the highest instantaneous temperature even reached $3750^{\circ} \mathrm{C}$, which is the sublimation temperature of the carbon fibers [30]. Eventually, an inverted conical ablation pit appeared in the center with a diameter of around $10 \mathrm{~mm}$. It is accordant with the experimental results as mentioned above.

During the laser ablation process, the samples can be rapidly heated to a quite high temperature. This result was also confirmed by lots of ablated fibers in the center according to the published works $[26,30]$. This temperature has reached to the decomposition temperature of $\mathrm{SiC}$ matrix (about $2700^{\circ} \mathrm{C}$ ) [35] and the sublimation temperature of carbon fibers. Thus, both SiC-based matrices and carbon fibers would be ablated. From the point of latent heat of sublimation, the latent heat of carbon fibers is $59.45 \mathrm{MJ} / \mathrm{kg}$, which is almost three times that of $\mathrm{SiC}$ matrix $(19.83 \mathrm{MJ} / \mathrm{kg})$. That means, the thermal stability of carbon fibers is better than that of SiC-based matrices. At the same time, carbon fibers are still surrounded by the SiC-based matrices. Thus, the needle-shaped carbon fibers can be observed in the central region, as shown in Fig. 4.

Meanwhile, the laser irradiation also provided samples a special low-oxygen environment. According to the analysis of possible reactions, carbon fibers and SiC-based matrices had been oxidized to gases which were made up of $\mathrm{CO}, \mathrm{SiO}$ and $\mathrm{SiO}_{2}$ at the beginning of the experiment. Then, a positive pressure atmosphere was formed on the laser ablation surface in area I. In this case, oxygen in the air near laser ablation surface would be nearly exhausted in a very short time. Under the positive pressure atmosphere, the oxygen in air is barely able to diffuse into the atmosphere of ablated surface during laser ablation process. In contrast of the conventional oxyacetylene flame ablation, the oxygen flow would provide a sufficient continuous oxygen-rich environment for samples. A large number of protective oxide layers were formed and widely covered on ablative surface. The oxidized and sheared fibers could be observed in the center region because of the high-speed oxygen and acetylene flow $[7,9,36]$. These phenomena had not been observed after the laser ablation, and proved the static low-oxygen environment provided from laser irradiation on the other hand. Therefore, the unoxidized nanolayered carbon phase remain in the center, as shown in Fig. 5.

Laser ablation mechanism of $\mathrm{C} / \mathrm{SiC}$ composite is shown in Fig. 8. The temperature had reached the sublimation and decomposition temperature of inner matrices, carbon fibers also reached its sublimation temperature. The mixed hot gases escaped to form a positive pressure atmosphere in area I. These created a static rich-carbon, low-oxygen and high-temperature condition on the surface. According to previous researches, in low oxygen partial pressure and high temperature region, the oxidation reaction type 
of $\mathrm{SiC}$ is actively oxidation [37]. SiC matrices were continuously consumed because of the gas phase product of actively oxidation. Subsequently, heat energy accumulated and high-temperature graphitization process occurred because of the special static richcarbon, low-oxygen and high-temperature condition. Therefore, lots of nanolayered carbon phase remained in the center, and these four composites appeared the similar LAR.

For C/SiC composites with different SiC-based matrices, due to the high temperature in the center region, no matrix existed after the ablation, and only residual carbon existed. So it is hard to say the introduced matrices (like Silicon, $\mathrm{Ti}_{3} \mathrm{Si}(\mathrm{Al}) \mathrm{C}_{2}$ etc.) can play the role to resist the laser ablation in this region. In this central area, the role of introduced matrices is to quickly consume the oxygen to promote the graphitization of residual carbon, so the residual carbon with a high graphitization degree existed. In the transition and edge regions, the introduction of these matrices could form a large and diverse variety of oxides, which could heal the cracks and holes and then prevent the direct contact of oxygen with internal materials. When the oxide film formed, the oxygen had to diffuse through the oxide film firstly, and then react with inner fibers and matrices. Thus, the presence of the oxidation products is helpful to improve the laser ablation resistant of the composites. So, it can be concluded that the introduced matrices are beneficial to the laser ablation resistance in the transition and edge regions.

The result shows that laser ablation of $\mathrm{C} / \mathrm{SiC}$ composites is controlled by chemical and physical erosion, mainly by the physical erosion in the center. Laser beam provides composites with a lowoxygen and high-temperature environment, which can cause the degradation or failure of materials. As a result, graphitization process mainly occurred in the center, and only needle-shaped carbon fiber and nanolayered carbon remained. Meanwhile, chemical erosion also existed during the laser ablation. A large amount of oxide formed in area II and area III, which covered the ablation surface, prevent the oxygen from diffusing inwardly and buffer the mechanical erosion of generated air flow.

\section{Conclusion}

In this work, the ablation behavior of four different $\mathrm{C} / \mathrm{SiC}$ composites were studied. These four composites were tested under certain laser irradiation environment. In this experimental condition, surface temperature in the center was heated to above $3500{ }^{\circ} \mathrm{C}$ in a very short time. Laser irradiation provided a special hightemperature and low-oxygen environment for thermostructural materials. After the laser ablation, only residual needle-shaped carbon fiber and nanolayered carbon remains in the center region. This is different from the reported results under other ablation conditions. Meanwhile, in the transition and edge regions, the introduced matrices increased the formation of oxides on the surface. The presence of these oxidized protective films significantly protected the materials from further erosion in these regions. As a result, it can be concluded that the laser ablation of $\mathrm{C} / \mathrm{SiC}$ composites is controlled by chemical and physical erosion, mainly by physical erosion in the center.

\section{Acknowledgements}

The authors are grateful for the supports of the National Natural Science Foundation of China (Project Nos. 51725205 and 51702261) and the 111 Project (B08040).

\section{References}

[1] X.W. Yin, L.F. Cheng, L.T. Zhang, Y.D. Xu, C. You, Mater. Sci. Eng. A 290 (2000) 89-94.

[2] W. Krenkel, F. Berndt, Mater. Sci. Eng. A 412 (2005) 177-181.

[3] R. Naslain, Des. Compos. Sci. Technol. 64 (2004) 155-170.

[4] B.L. Zou, Z.S. Khan, L.J. Gu, X.Z. Fan, W.Z. Huang, Y. Wang, Z. Yu, C.J. Wang, K.Y. Yang, H.M. Ma, X.Q. Cao, Corros. Sci. 62 (2012) 192-200.

[5] F. Christin, Adv. Eng. Mater. 4 (2002) 903-912.

[6] S. Schmidt, S. Beyer, H. Knabe, H. Immich, R. Meistring, A. Gessler, Acta Astronaut. 55 (2004) 409-420.

[7] X.M. Fan, X.W. Yin, L. Wang, L.F. Cheng, L.T. Zhang, Corros. Sci. 74 (2013) 98-105.

[8] G.M. Song, S.B. Li, C.X. Zhao, W.G. Sloof, S. van der Zwaag, Y.T. Pei, J.Th.M. De Hosson, J. Eur. Ceram. Soc. 31 (2011) 855-862.

[9] L. Luo, Y.G. Wang, L.P. Liu, L.Y. Duan, G.L. Wang, Y.H. Lu, Carbon 103 (2016) 73-83.

[10] S.F. Tang, J.Y. Deng, S.J. Wang, W.C. Liu, Corros. Sci. 51 (2009) 54-61.

[11] Y. Wang, Y.D. Xu, Y.G. Wang, L.F. Cheng, L.T. Zhang, Mater. Lett. 64 (2010) 2068-2071.

[12] L. Luo, Y.G. Wang, L.Y. Duan, L.P. Liu, G.L. Wang, J. Eur. Ceram. Soc. 36 (2016) 3801-3807.

[13] Q. Feng, Z. Wang, H.J. Zhou, P. He, L. Gao, Y.M. Kan, X.Y. Zhang, Y.S. Ding, S.M. Dong, Ceram. Int. 40 (2014) 1199-1204.

[14] S.F. Tang, C.L. Hu, J. Mater. Sci. Technol. 33 (2017) 117-130.

[15] S.F. Tang, J.Y. Deng, W.C. Liu, K. Yang, Carbon 44 (2006) 2877-2882.

[16] D.J. Liu, X.Q. He, Q. Duan, L.J. Wang, Y. Zhou, Laser J. 23 (2002) 5-6.

[17] Q.H. Lou, J. Zhou, Z.J. Wang, Laser Technol. 03 (2003) 161-165.

[18] G.P. Perram, M.A. Marciniak, M. Goda, in: Proceedings of SPIE - The International Society for Optical Engineering 5414, 2004, pp. 1-25.

[19] Q.M. Liu, L.T. Zhang, F.R. Jiang, J. Liu, L.F. Cheng, H. Li, Y.G. Wang, Surf. Coat. Technol. 205 (2011) 4299-4303.

[20] G.D. li, X. Xiong, K.L. Huang, T. Nonferr, Metal. Soc. 19 (2009) 689-695.

[21] A. Slocombe, L. Li, Appl. Surf. Sci. 154 (2000) 617-621.

[22] S. Costil, S. Lukat, C. Langlade, C. Coddet, Appl. Surf. Sci. 255 (2008) 2425-2432.

[23] P.E. Dyer, in: Proceedings of SPIE - The International Society for Optical Engineering 4760, 2002, pp. 34-42.

[24] P.E. Dyer, J. Sidhu, J. Appl. Phys. 57 (1985) 1420-1422.

[25] R. Srinivasan, Chem. Rev. 89 (1984) 1303-1316.

[26] Y.G. Tong, S.X. Bai, H. Zhang, Y.C. Ye, Ceram. Int. 39 (2013) 6813-6820.

[27] M. Su, L.F. Cheng, X.G. Luan, L.T. Zhang, Act. Mater. Compos. Sinica 30 (2013) 37-47.

[28] Y.Z. Ma, X.W. Yin, X.M. Fan, P.F. Ju, X.L. Dang, Mater. Sci. Eng. A 712 (2018) $397-405$.

[29] X.M. Fan, X.W. Yin, X.Y. Cao, L.Q. Chen, L.F. Cheng, L.T. Zhang, Compos. Sci. Technol. 115 (2015) 21-27.

[30] W.M. Haynes, CRC Handbook of Chemistry and Physics, CRC Press, Boca Raton, 2014, pp. 723-876.

[31] M. Inagaki, M. Shiraishi, M. Nakamizo, Y. Hishiyama, Carbon Tech. 13 (1991) 739-743.

[32] M. Yudasaka, T. Komatsu, T. Ichihashi, S. Iijima, Chem. Phys. Lett. 278 (1997) $102-106$.

[33] Z.Q. Li, H.J. Li, K.Z. Li, S.Y. Zhang, Mater. Lett. 74 (2012) 118-120.

[34] X.H. Li, Q.Z. Yan, Y.Y. Mi, Y.J. Han, X. Wen, C.C. Ge,Chin. Phys. B 24 (2015), 026103.

[35] Y.S. Pan, Y.D. Xu, Z.F. Chen, L.F. Cheng, L.T. Zhang, D.S. Xiong, Ordnance Mater. Sci. Eng. 29 (2006) 17-20.

[36] X.T. Shen, K.Z. Li, H.J. Li, H.Y. Du, W.F. Cao, F.T. Lan, Carbon 48 (2010) 344-351.

[37] H. Ping, G.L. Wang, W. Zhi, Corros. Sci. 51 (2009) 2724-2732. 